Article

\title{
Effect of Winter Oilseed Rape Cropping on the Development of the Sugar Beet Cyst Nematode, Heterodera schachtii, and Control of Volunteer Plants as a Trap Crop Method
}

\author{
Matthias Daub \\ Julius Kühn-Institute, Institute of Plant Protection in Field Crops and Grassland, Dürener Str. 71, \\ D-50189 Elsdorf, Germany; matthias.daub@julius-kuehn.de
}

Received: 6 February 2020; Accepted: 28 February 2020; Published: 4 March 2020

\begin{abstract}
The integration of oilseed rape (OSR) into sugar beet rotation systems is restricted due to the very good host status of OSR for the beet cyst nematode (BCN) Heterodera schachtii. In contrast to sugar beet, the cultivation of winter OSR covers a longer period, but at a lower soil temperature regime. Thus, presumably one or two generations of $\mathrm{BCN}$ may develop during the cultivation of winter OSR, resulting in moderate multiplication rates of $1-2$ in the present study. This multiplication rate was year-dependent, but not affected by different sowing times. For the first time, the present study identified volunteer OSR emerging in high densities post-harvest as a major risk for a high multiplication of $\mathrm{BCN}$ at optimum temperatures. The emergence of $\mathrm{BCN}$ females with offspring was observed very early, resulting in a significant population increase before 350 -degree days $\left(>8^{\circ} \mathrm{C}\right)$ in inoculation experiments and in field investigations. Conducting treatment trials with glyphosate to control volunteer OSR in micro-plots and field experiments confirmed effective suppression of BCN reproduction when growth of volunteer OSR was interrupted at 250-350-degree days. Thus, data gained from $\mathrm{BCN}$ reproduction studies under controlled and field conditions provided a unique basis for the development of a trap crop method. The degree day model has been successfully implemented as part of an open access management tool.
\end{abstract}

Keywords: volunteer plants; beet cyst nematodes; degree day model; glyphosate; Brassica napus; trap crop

\section{Introduction}

The beet cyst nematode (Heterodera schachtii Schmidt, 1871) is a major pest of sugar beet, with severe economic damage potential [1], which occurs worldwide throughout different geographic and climatic regions [2]. Oilseed rape (OSR) is considered tolerant against Heterodera schachtii, but is a very good host with high reproduction potential for the nematode [3].

Ever since Julius Kühn [4] identified oilseed rape (Brassica napus L.) as a host of the beet cyst nematode (BCN), it has been widely accepted that the integration of OSR into crop rotation systems with sugar beet should be avoided $[5,6]$ to minimize the potential risks of an uncontrolled population increase of $\mathrm{BCN}$ [7]. Resistance against BCN was transferred successfully from Raphanus sativus L. to Brassica napus L., resulting in a new BCN-resistant plant Raparadish $(\times$ Brassicoraphanus, $2 n=38)$ with low agricultural value [8]. More recently, resistance genes BvcZR3 and BvHs1pro-1 from clones of resistant sugar beet translocation lines were transferred into oilseed rape, which resulted in highly resistant transgenic OSR lines [9]. Nevertheless, BCN-resistant OSR cultivars are not yet available to growers in Europe. 
The cultivation of winter OSR, which is common in central Europe, covers a vegetation period of about 10 months, from August/September to July. Within this period, the development of one generation of $\mathrm{BCN}$ under field conditions was confirmed in earlier studies $[10,11]$, if sowing was as early as August. A crucial factor for the onset and completion of a second generation in winter OSR is considered to be the soil temperature during early spring [12]. An average temperature increase and the more frequent occurrence of warm winters are predicted in future climate scenarios for central Europe $[13,14]$, which might enhance the potential risk of OSR for the multiplication of BCN. In contrast to OSR line varieties that were commonly sown in mid-August, current OSR hybrids enable late sowing times, until September, where soil temperature decreases and the activity of BCN starts to slow down. Thus, a delay of sowing times could be used to reduce the risk of $\mathrm{BCN}$ reproduction. The impact of different sowing times of OSR on the reproduction of BCN has not yet been investigated.

During the ripening of OSR, as pods already open and seeds come out, especially at harvest, there is a yield loss of $4000-7000 \mathrm{seed} / \mathrm{m}^{2}$ [15]. A part of these seeds germinate post-harvest as volunteer oilseed rape (vOSR) in the same field and have to be treated as a weed [16]. Volunteer oilseed rape has not been considered as a risk for the reproduction of $\mathrm{BCN}$, even though it provides the most favourable conditions for $\mathrm{BCN}$ reproduction. These include a high density of a good host and an optimum soil temperature of about $25{ }^{\circ} \mathrm{C}$ [17]. About $17 \%$ of the initial seed bank was found to persist in the following crop, and $1.6 \%$ was retained until four years after the first occurrence [18]. If vOSR remains uncontrolled in the field, it may provide a "green bridge" for BCN in crop rotations with sugar beet. Deviating from a classical weed management, where repeated tillage should foster high germination rates over time, the development of vOSR needs to be interrupted at a certain stage to prevent completion of the $\mathrm{BCN}$ lifecycle and avoid the production of viable eggs and juveniles. In the search for a control strategy against BCN, Julius Kühn [19] developed a trap crop method that was primarily based on this effect. Kühn recommended using OSR and other cruciferous host plants for the cultivation of trap crops during summer and the destruction of the plants 25 days after seedling emergence. As a checkup, the occurrence of $\mathrm{BCN}$ males in the rhizosphere set the right time for the control of plants and nematodes.

In Germany, the current knowledge on the effect of winter-OSR cropping on the development of $\mathrm{BCN}$ is primarily based upon ancient studies, and the role of vOSR has not yet been considered. Growing conditions have changed and enable a variation in sowing times today. Temperature-based degree day models enable growers to meet crucial time windows for the control of volunteer plants which host certain $\mathrm{BCN}$ development stages. Therefore, a correlation between temperature and population dynamics must be found. Aiming to deliver the scientific data basis for this approach, the objectives of this study were (1) to detect the time window for the emergence of females with offspring and the time of significant nematode population increase under winter oilseed rape, (2) to investigate the impact of different sowing times of cultivated winter OSR on the reproduction of nematodes under field conditions, (3) to quantify nematode reproduction caused by volunteer OSR in the field and (4) to identify the time window for the effective control of volunteer OSR to achieve maximum suppression of nematodes.

\section{Materials and Methods}

\subsection{General Methods}

The commercial OSR cultivar NK Fair was pre-tested as highly susceptible for BCN following the bioassay for resistance testing of trap crops [20]. The commercial OSR cultivar NK Fair was used in all experiments from the period 2008 to 2010. Chemical control of vOSR was applied with glyphosate ( $350 \mathrm{~g} / \mathrm{L}, 3.5 \mathrm{~L} / \mathrm{ha}$ ) in all experiments using a pressure-regulated backpack sprayer (Bierchmeier, Stetten, Switzerland) in field experiments, or a hand sprayer (Mesto, Freiberg, Germany) in micro-plot trials. Glyphosate application was applied according to a degree day (DD) model, which cumulated average daily soil temperatures above $8{ }^{\circ} \mathrm{C}$, starting at the time of vOSR emergence. Treatments of vOSR at 
certain degree days varied between 12 and 24 DD, or approximately 1-2 days, due to the requirement on weather conditions for spray applications. Soil temperature was recorded continuously on site at 10-15 cm soil depth by temperature probes linked to a field data logger (EM 50, Decagon, Hopkins Ct. Pullman, WA, USA). In field experiments, 12 soil samples per plot were taken manually with a split-core auger (inner diameter $5 \mathrm{~cm}$ ) from the topsoil ( $30 \mathrm{~cm}$ depth). In micro-plot (MP) trials, 10 soil samples were taken by hand using a core auger (inner diameter $1.5 \mathrm{~cm}$ ), also from the upper $30 \mathrm{~cm}$. Samples of each plot or micro-plot were merged to a mixed sample of $4-5 \mathrm{Kg}$ (field plot) and $1 \mathrm{Kg}$ (micro-plot). Samples were kept in a cold store at $4-5{ }^{\circ} \mathrm{C}$ until analysis. The population density of $\mathrm{BCN}$ was determined in a homogenized subsample of $300 \mathrm{~g}$ by a modified density centrifugation technique [21], using an $\mathrm{MgSO} 4$ solution $(1.26 \mathrm{~g} / \mathrm{mL})$.

\subsection{Pot Experiments on Interaction between $B C N$ and OSR as Host Plant}

Two greenhouse trials were conducted during May and June in 2008 and 2009, covering a period of $6-7$ weeks. Temperature was controlled at $20 \pm 5^{\circ} \mathrm{C}$. Pots $(450 \mathrm{~mL})$ were filled with loess originating from the Rhineland area in Germany as a standard substrate, as described by Müller and Rumpenhorst [20] and 12 seeds were sown per pot. After germination, plant density was singled to a standard density of 10 plants per pot. BCN was inoculated as cysts mixed into the soil prior to sowing. Initial population density $(\mathrm{Pi})$ could be adjusted to $860 \mathrm{e} \& \mathrm{j} 2 / 100 \mathrm{~mL}$ in 2008 and $280 \mathrm{e} \& \mathrm{j} 2 / 100 \mathrm{~mL}$ in 2009. A BCN standard population (Schach 0 ) was used for inoculation derived from a stock population, which was continuously reared with OSR as a susceptible host. Applying a serial of increasing degree days, six sampling dates after the emergence of OSR were defined, which were realized differently in both years. In 2008, sampling was conducted on the following degree days $\left(>8^{\circ} \mathrm{C}\right) /$ days after sowing (DAS): DD 135/DAS 16 (date 1), 225/29 (2), 324/39 (3), 396/45 (4), 441/51 (5), 522/58 (6). In 2009, sampling covered the following degree days $\left(>8^{\circ} \mathrm{C}\right)$ / days after sowing: 123/16 (1), 199/24 (2), 318/36 (3), 405/45 (4), 456/50 (5), 550/58 (6). To calculate degree days, temperature in pots were detected by four temperature probes inserted into the substrate of pots at distant positions and recorded by a data logger (EM 50, Decagon, Hopkins Ct. Pullman, WA, USA). At each sampling date, BCN were extracted from 10 pots each. Roots were separated from soil, washed and milled using a standard lab blender. An acid fuchsin solution was added to the root suspension of 10 plants and cooked for four minutes at $800 \mathrm{~W}$ in a microwave to dye all nematodes stages. All nematode stages (J2, J3, J4, pre-adult males and females) were counted seperately five times from $1 \mathrm{~mL}$ of diluted $(30-50 \mathrm{~mL})$ root suspension. Cyst and females were extracted from $350 \mathrm{~g}$ of soil per pot in accordance with the modified density centrifugation technique used for field samples.

\subsection{Field Experiments on Winter OSR Effects}

Two field experiments on the effect of winter OSR cultivation on the multiplication of BCN, applying different sowing times, were conducted in the period 2007-2008 and 2009-2010 in the Rhineland region in Western Germany. The trial in 2007-2008 was conducted on an experimental field in Elsdorf and the trial in 2009-2010 was carried out on a farmed field in Titz. Both fields were maintained as part of a sugar beet rotation system where winter wheat was cropped prior to winter OSR. Both fields showed a natural BCN infestation at a comparable mean Pi density (Elsdorf: 1255 e\&j2/100 mL; Titz: 1403 e\&j2/100 mL). Soil preparation, application of fertilizer, plant protection measurements and harvest were carried out according to the local practice and with practical farm machinery. The applied sowing times for OSR considered the practical range of early, moderate and late times between calendar weeks 35 and 37. In 2007, OSR was sown out on 27th August (early), 4th September (moderate) and 14th September (late), and in 2009 sowing was conducted on 27th August, 1st September and 8th September. Each variation was sown in strips covering 10 plots for the determination of BCN population densities. Each sampling plot was sized $22.5 \mathrm{~m}^{2}$. Soil sampling was restricted to the inner part of $14 \mathrm{~m}^{2}$, considering a $1 \mathrm{~m}$ corridor between the edge and inner part. Initial population density (Pi1) was detected in samples taken 1-2 days prior to sowing and final population 
density (Pf1) was detected in samples taken 1 week after harvest and before the appearance of vOSR. In 2008, the sampling date for Pf1 was 29th July, and in 2010 Pf1 samples were taken on 25th July.

\subsection{Field Experiments on Effects of vOSR Treatment}

Following OSR cultivation, one field trial on the effect of the chemical control of vOSR on BCN reproduction was carried out in 2008, in Elsdorf, and 2010 in Titz. Fields showed a natural distribution of vOSR after OSR harvest ranging, from 100 to 500 Plants $/ \mathrm{m}^{2}$ at 400 DD. vOSR was treated with glyphosate after $250 \mathrm{DD}$ and $350 \mathrm{DD}$. Treatments were compared to an untreated control and one control variation, where the occurrence of vOSR was suppressed completely by glyphosate application. Sampling plots of $14 \mathrm{~m}^{2}$ were arranged randomly in a split block design with seven replications of each treatment. Pi2 samples were taken before the occurrence of vOSR and Pf2 samples were taken at the end of the vegetation period in October, in accordance to the technique described previously.

To detect the population dynamics of $\mathrm{BCN}$ during the unimpeded development of vOSR, one area was sampled in Titz in 2010 and in Linnich in 2016. The area was divided into two neighbouring strips, each consisting of 10 sampling plots of $14 \mathrm{~m}^{2}$. In one strip, the occurrence of vOSR was suppressed by glyphosate application, and in the neighbouring strips, vOSR was not treated. Pi2 sampled were taken before occurrence of vOSR and successively Pf2 samples were taken at 50 DD, 180 DD, 350 DD, 410 DD and 460 DD in 2011 and at 6 DD, 118 DD, 200 DD, 304 DD, and 410 DD in 2017

\subsection{Micro-Plot Experiments on Effects of Simulated Volunteer Oilseed Rape Treatments}

To measure the effect of glyphosate treatment of simulated volunteer oilseed rape (svOSR) on $\mathrm{BCN}$ reproduction two trials were conducted in micro-plots (MP) in 2008 and 2009. All MPs carried a sufficient initial BCN population density (2008: $1895 \pm 1216 \mathrm{e} \& \mathrm{j} 2 / 100 \mathrm{~mL} ; 2009: 2090 \pm 1383 \mathrm{e} \& \mathrm{j} 2 / 100$ $\mathrm{mL}$ ). Aiming at a high plant density of above 500 plants $/ \mathrm{m}^{2}$, vOSR was sown out with $3 \mathrm{~g} / \mathrm{m}^{2}$ in each MP. Each MP measured $1 \mathrm{~m}^{2}$ and received $5 \mathrm{~g}$ nitrogen/MP. Seeds were sown out at the time of natural vOSR germination on 5th August (2008) and 27th July (2009). Plots were watered by a sprinkler irrigation if necessary. vOSR was treated with glyphosate according to the prescribed DD-Model at an early treatment time (250 DD), a moderate treatment time (300 DD) and a late treatment time (350 DD). Glyphosate treatments were compared with a non-treated control. All treatments and the control were distributed randomly in MP with six replications. Pi samples were taken before sowing and Pf samples at the end of the vegetation period in October.

\subsection{Statistical Analyses}

Multiplication rates were calculated from population densities $(\mathrm{Pf} / \mathrm{Pi})$ and $\log (\mathrm{x}+1)$ transformed. Data on population dynamics of BCN in the vOSR strips and in pot experiments were not transformed. Data were tested on normal distribution by Shapiro-Wilks Test. Differences between multiplication rates of treatments or sowing times were analyzed by ANOVA post hoc test (Fisher LSD). Likewise, the population dynamics of $\mathrm{J} 2$ in roots, $\log (x+1)$ transformed data from cysts and female counts in pot experiments were analyzed by ANOVA post hoc test (Fisher LSD). Data on population dynamics in the vOSR strips were tested by $t$-test for differences between the treatments only within the same sampling time. Residuals were tested for homogeneity of variance (Lévene test) and normal distribution. Exceptionally, the population dynamics of eggs and juveniles extracted from cysts or females in pot experiments were tested with the non-parametric Kruskal Wallis ANOVA. Year effects vs. treatment effects were tested using main factorial ANOVA in the GLM procedure. All statistical analyses were processed by STATISTICA 10.0 (StatSoft, Inc. 2011, Tulsa, OK, USA). 


\section{Results}

\subsection{Pot Experiments on Interaction between BCN and OSR as Host Plant}

Juvenile stage $\mathrm{J} 2$ was the most dominant development stage detected in OSR roots at the first sampling date $(45 \%-60 \%$ of all individuals) and from sampling date 4 ( $>80 \%)$ onwards. Accordingly, the population dynamics of $\mathrm{J} 2$ in both years reached a significant maximum of $850 \mathrm{~J} 2 / \mathrm{g}$ fresh roots in 2008 and $1482 \mathrm{~J} 2 / \mathrm{g}$ fresh root in 2009 (Figure 1). A second invasion of J2 in both years could be detected during the last two sampling dates when 440 DD were exceeded (50-51 DAS), though at significantly lower population densities comparing to the first peak. Despite the increased root weight of OSR plants from $0.78 \pm 0.17 \mathrm{~g}$ (mean 2008/2009 $\pm \mathrm{SD}$ ) at the first sampling date to $8.1 \pm 1.9 \mathrm{~g}$ at the final sampling date, no correlation $\left(r^{2}=0.23, p<0.01\right)$ was found between root weight and $\mathrm{J} 2$ density per $\mathrm{g}$ root weight. The abundance of females extracted from soil significantly increased at the second sampling date, when 199 DD were exceeded in both years (Table 1). At the last sampling date, the abundance of females further increased significantly, and likewise reached about 200 females $/ 100 \mathrm{~mL}$ in both years. The abundance of cysts also significantly increased at the final sampling date, but at a lower level than that of females. When comparing population densities of eggs and juveniles derived from either cysts or females (Figure 2) a similar trend was observed in both years. First, eggs and juveniles from females already appeared at the second sampling date (24-29 DAS) at fairly low densities. A significant increase in this population was observed at the third sampling date $(5704 \pm 3876$ e\&j2/100 mL), which presumably started between degree day 199 and 324.

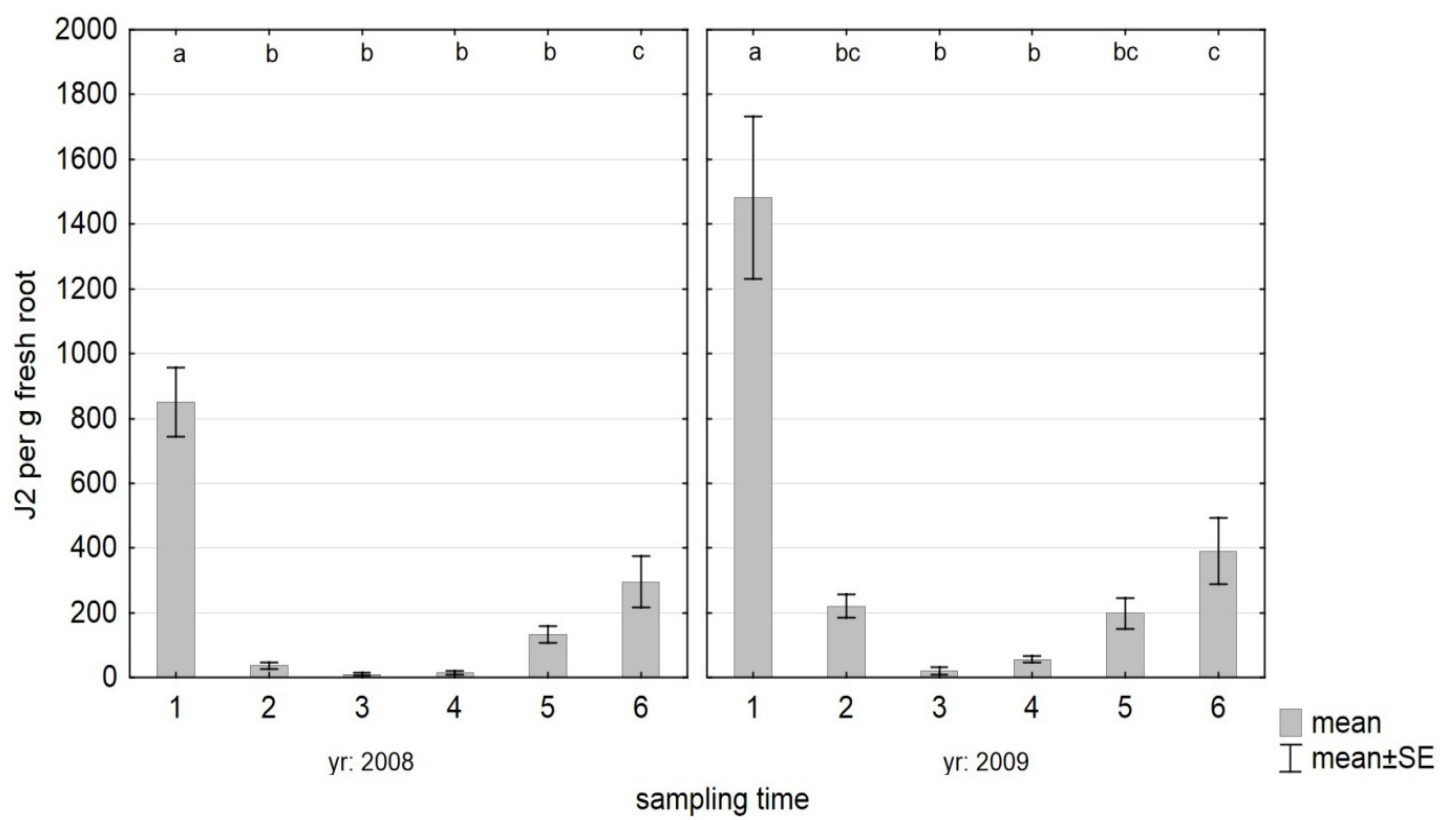

Figure 1. Population dynamics of beet cyst nematode (BCN) juveniles (J2) in oilseed rape OSR roots at six sampling dates after sowing, referring to degree days $\left(>8^{\circ} \mathrm{C}\right)$ in the year 2008: $135 \mathrm{DD}$ (date 1), 225 (2), 324 (3), 396 (4), 441 (5), 522 (6) and in the year 2009: 123 (1), 199 (2), 318 (3), 405 (4), 456 (5), 550 (6); means only within years were tested by Fischer LSD Test $(p<0.05)$, different letters indicate significant differences. 
Table 1. Abundance of beet cyst nematode (BCN) females and cysts in soil from pots with oilseed rape (OSR) plants at different sampling dates after sowing; means between sampling dates only within years were tested by Fischer LSD Test $(p<0.05)$ using $\log (x+1)$ transformed data, different letters $(a-c)$ indicate significant differences of cyst and female numbers respectively between sampling dates.

\begin{tabular}{|c|c|c|c|c|c|c|c|c|c|c|}
\hline \multirow[b]{2}{*}{$\begin{array}{l}\text { Sampling } \\
\text { Date }\end{array}$} & \multicolumn{4}{|c|}{2008} & \multicolumn{6}{|c|}{2009} \\
\hline & $\mathrm{DD}\left(>8^{\circ} \mathrm{C}\right)$ & Cysts/100 mL & & Females/100 mL & & $\mathrm{DD}\left(>8^{\circ} \mathrm{C}\right)$ & Cysts/100 mL & & Females/100 mL & \\
\hline Initial & 135 & $12.0 \pm 0.9$ & $\mathrm{a}$ & $0.0 \pm 0.0$ & $\mathrm{a}$ & 123 & $8.4 \pm 0.4$ & $\mathrm{a}$ & $0.0 \pm 0.0$ & a \\
\hline 2nd & 225 & $10.8 \pm 1.3$ & $\mathrm{a}$ & $23.0 \pm 6.3$ & $\mathrm{~b}$ & 199 & $8.2 \pm 0.7$ & $\mathrm{a}$ & $85.1 \pm 16.0$ & $\mathrm{~b}$ \\
\hline final & 522 & $25.2 \pm 5.4$ & $\mathrm{~b}$ & $199.6 \pm 54.0$ & c & 550 & $71.9 \pm 54.0$ & $\mathrm{~b}$ & $216.5 \pm 25.0$ & c \\
\hline
\end{tabular}




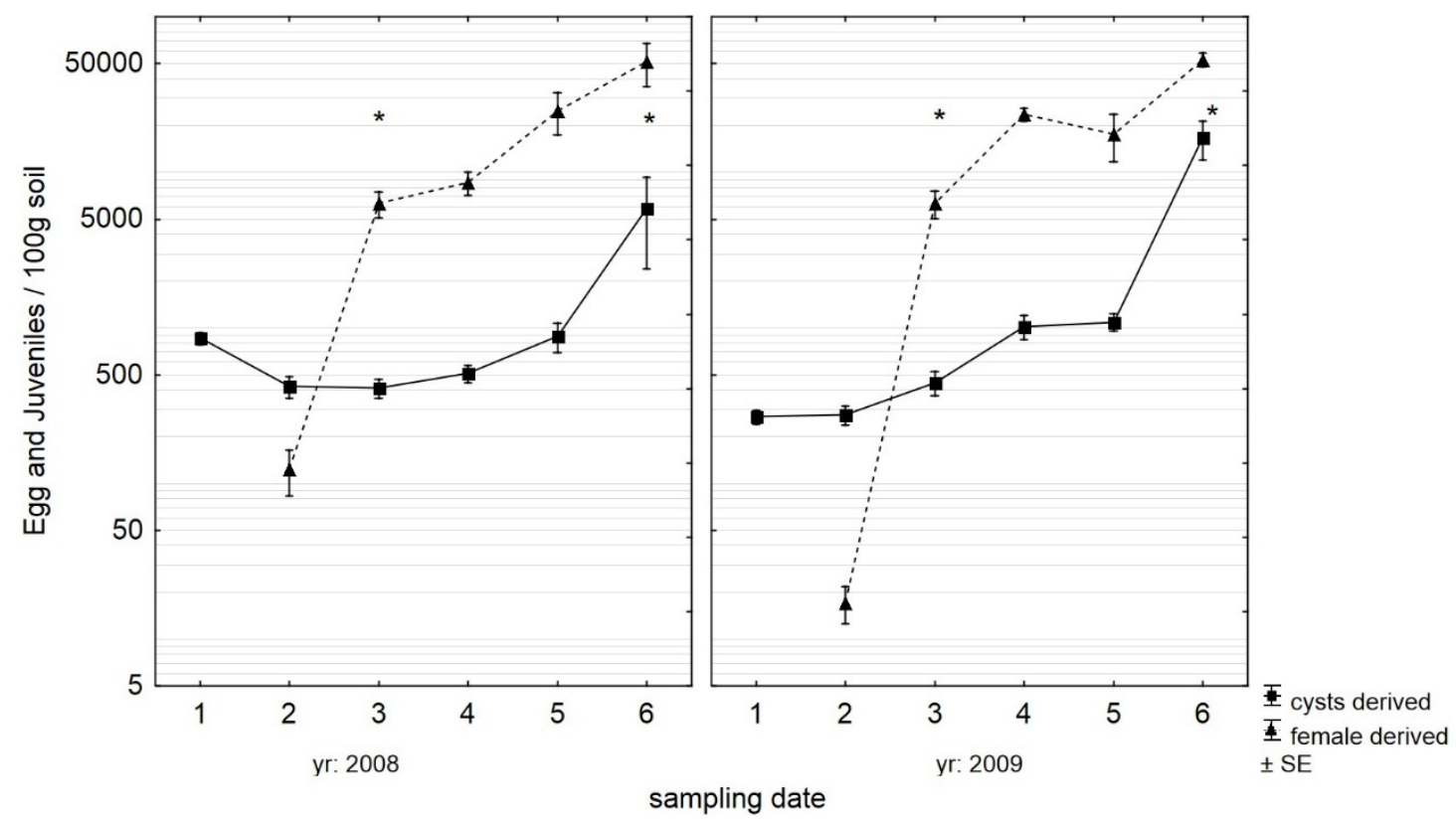

Figure 2. Population dynamics of beet cyst nematode (BCN) eggs and juveniles per $100 \mathrm{~g}$ of soil extracted from mature cyst and females separately from pots with oilseed rape (OSR) plants at six sampling dates after sowing referring to degree days $\left(>8^{\circ} \mathrm{C}\right)$ in the year 2008: $135 \mathrm{DD}$, (date 1), 225, (2), 324, (3), 396, (4), 441, (5), 522, (6) and in the year 2009: 123, (1), 199, (2), 318, (3), 405, (4), 456, (5), 550, (6); * significant increase in population in comparison to minimum population density, Kruskal Wallis ANOVA $(p<0.05)$.

\subsection{Field Experiments on Winter OSR Effects}

Sowing times ranging from 27th August to 14th September did not affect multiplication rates (Pf/Pi) of BCN in field trials in both years (Table 2). This was evident despite significant variation in initial population densities (Pi) between plots, with different sowing times in each year. Mean multiplication rates of BCN under winter OSR in 2008 reached values between 1.6 and 2.3, and thus were significantly higher than rates observed in 2010, which effectively showed no change in population density or even a reduction in the BCN population of $10 \%-20 \%$.

Table 2. Mean multiplication rates (Pf1/Pi1) and initial population densities Pi1 of beet cyst nematode $(\mathrm{BCN})$ under winter oil seed rape (OSR) at different sowing times.

\begin{tabular}{ccccc}
\hline & \multicolumn{2}{c}{$\mathbf{2 0 0 8}$} & $\mathbf{P i}_{\mathbf{1}}$ \\
\hline Drilling Time & $\mathbf{P f}_{\mathbf{1}} / \mathbf{P} \mathbf{i}_{\mathbf{1}}$ & $\mathbf{P i}_{\mathbf{1}}$ & $\mathbf{P f}_{\mathbf{1}} / \mathbf{P i}_{\mathbf{1}}$ & $531 \pm 59 \mathrm{a}$ \\
\hline early & $1.6 \pm 0.3 \mathrm{a}$ & $1547 \pm 166 \mathrm{a}$ & $1.0 \pm 0.2 \mathrm{~b}$ & $721 \pm 59 \mathrm{~b}$ \\
moderate & $2.1 \pm 0.4 \mathrm{a}$ & $829 \pm 75 \mathrm{~b}$ & $0.9 \pm 0.1 \mathrm{~b}$ & $608 \pm 45 \mathrm{a}$ \\
\hline late & $2.3 \pm 0.4 \mathrm{a}$ & $874 \pm 91 \mathrm{~b}$ & $0.8 \pm 0.1 \mathrm{~b}$ & \\
\hline$P_{\text {drilling time } A}$ & & 0.66 & \\
$P_{\text {year } B}$ & & $<0.01$ & \\
$P_{A^{*} B}$ & & 0.19 & \\
\hline
\end{tabular}

Mean \pm standard error; Differences in Pf1/Pi1 and Pi separately between drilling times were tested with $\log (x$ $+1)$ transformed data using Fischer LSD Test $(p<0.05)$; different letters $(a-b)$ indicate significant differences of $\mathrm{Pf}_{1} / \mathrm{Pi}_{1}$ and $\mathrm{Pi}_{1}$ respectively between sowing times; Factors of drilling time $(\mathrm{A})$, year $(\mathrm{B})$ and cross effects $\left(\mathrm{A}^{*} \mathrm{~B}\right)$ on multiplication rates $\mathrm{Pf} / \mathrm{Pi}$ ANOVA.

During the period where Winter OSR was cropped (August to July), average soil temperature in $10 \mathrm{~cm}$ depth reached $10.3{ }^{\circ} \mathrm{C}$ in 2008, while it was $9.4^{\circ} \mathrm{C}$ in 2010 (Figure 3). As a result, in 2010, temperature sums above $8{ }^{\circ} \mathrm{C}$ were 168 to $189 \mathrm{DD}$ lower than in 2008 (Table 3). On the other hand, 
the difference in temperature sum between early and late drilling was approximately 120 to 140 DD. In both years, early sowing times achieved over 1100 DD.

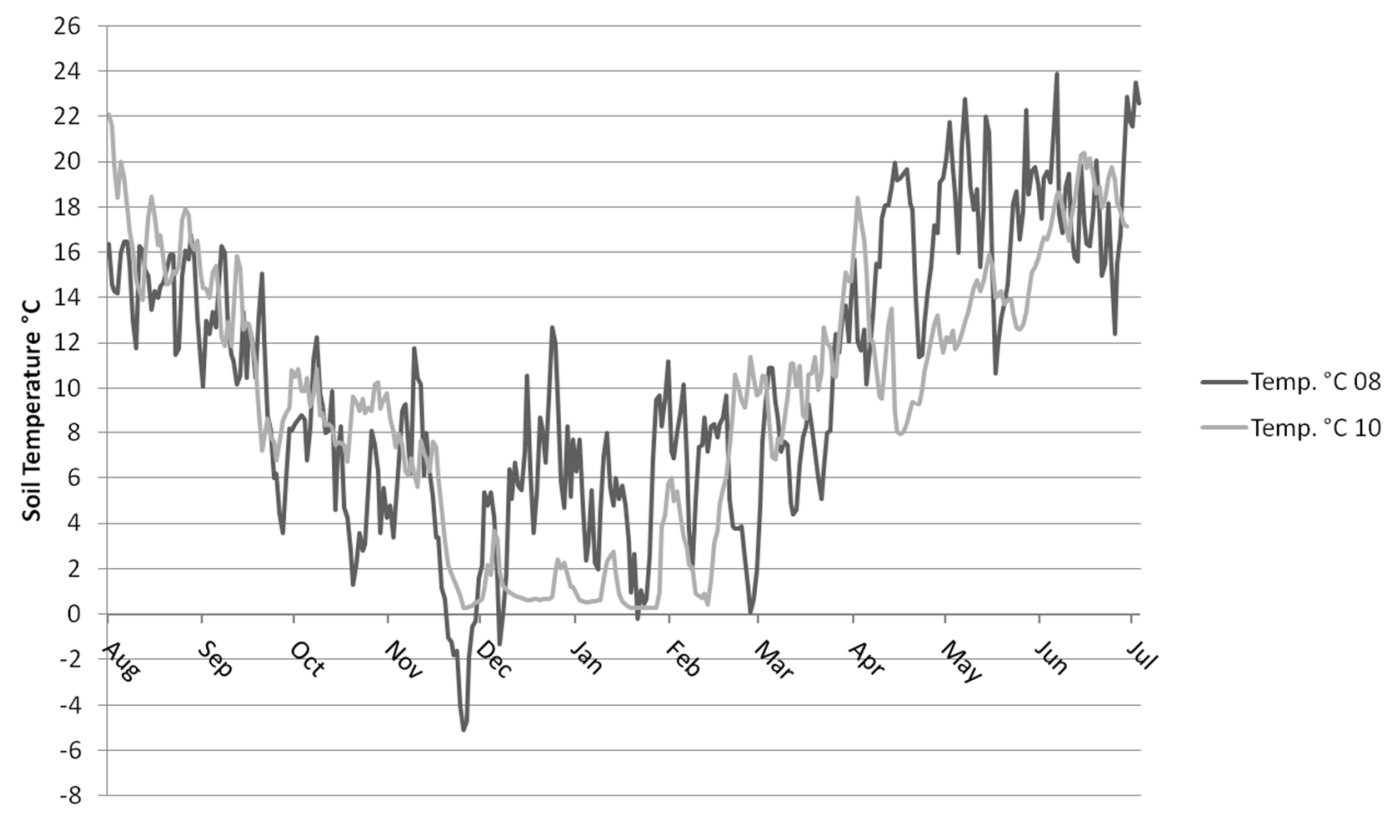

Figure 3. Soil temperatures at $10 \mathrm{~cm}$ depth during the cultivation of winter oilseed rape from August to July in Elsdorf (2008) and Titz (2010).

Table 3. Final degree days $\left(>8^{\circ} \mathrm{C}\right)$ calculated from average soil temperature in $10 \mathrm{~cm}$ soil depth from sowing to harvest under winter oil seed rape at different sowing times.

\begin{tabular}{lcc}
\hline & \multicolumn{2}{c}{ Degree Days $\left(>\mathbf{8}{ }^{\circ} \mathbf{C}\right)$} \\
\hline Sowing Time & $\mathbf{2 0 0 8}$ & $\mathbf{2 0 1 0}$ \\
\hline early & 1294 & 1107 \\
moderate & 1229 & 1045 \\
late & 1156 & 988 \\
\hline
\end{tabular}

\subsection{Field Experiments on Effects of vOSR Treatment}

In succession of the winter OSR harvest 2008, volunteer oilseed rape (vOSR) emerged on 14th July, which was approximately 3 weeks earlier than in 2010, due to favourable weather conditions. Plants treated with glyphosate at $350 \mathrm{~g} / \mathrm{L}$ and $3.5 \mathrm{~L} /$ ha died off within 6 days after application. In general, the volunteer plants emerged asynchronously, resulting in different plant development stages (one to five leaves unfolded) being present post-harvest in the same field. For this reason, glyphosate had to be applied several times to control upcoming plants in control plots. In 2008, the plant density of vOSR slightly varied between plots according to the natural growth pattern, whereas in 2010, high plant densities homogenously occurred throughout the whole trial area. The time elapsed between emergence and control of vOSR at 350 DD was 29 days in 2008 and 36 days in 2010. Trials were terminated at the end of season (first week of October) by taking Pf samples. Within the period between the emergence of vOSR and Pf sampling, approximately 780 DD were achieved in 2008, with an average soil temperature of $17.8^{\circ} \mathrm{C}$, while in 2010 it was approximately $500 \mathrm{DD}$ with a lower average soil temperature of $15.9^{\circ} \mathrm{C}$.

The highest multiplication rates (Pf2/Pi2) of $\mathrm{BCN}$ were detected when growth of vOSR was not controlled (Figure 4). Pf2/Pi2 values in these plots was $2.35(\log (x+1)=0.51)$ in 2008 and $1.65(\log (x+1)=0.4)$ in 2010. Likewise, final population (Pf2) reached densities of 3810 eggs and juveniles/100 mL in 2008, and 843 eggs and juveniles/100 mL in 2010. In comparison to uncontrolled 
vOSR, control of vOSR at $250 \mathrm{DD}$ and $350 \mathrm{DD}$ achieved significantly lower multiplication rates in both years, ranging between 0.4 and $0.9(\log (x+1)$ : 0.14 to 0.27$)$. No difference in multiplication rates between $250 \mathrm{DD}, 350 \mathrm{DD}$ or no plants could be observed, although the lowest multiplication rates were measured in plots where vOSR was controlled at 250 DD in 2010. Merging results from both years, a significant effect on multiplication rates could be observed by treatments and year (Table 4). Initial population density (Pi2) was not different between treatments but significantly different between years. In 2008, Pi2 density was 1729 eggs and juveniles/100 mL, and in 2010 Pi2 density was 524 eggs and juveniles/100 mL.
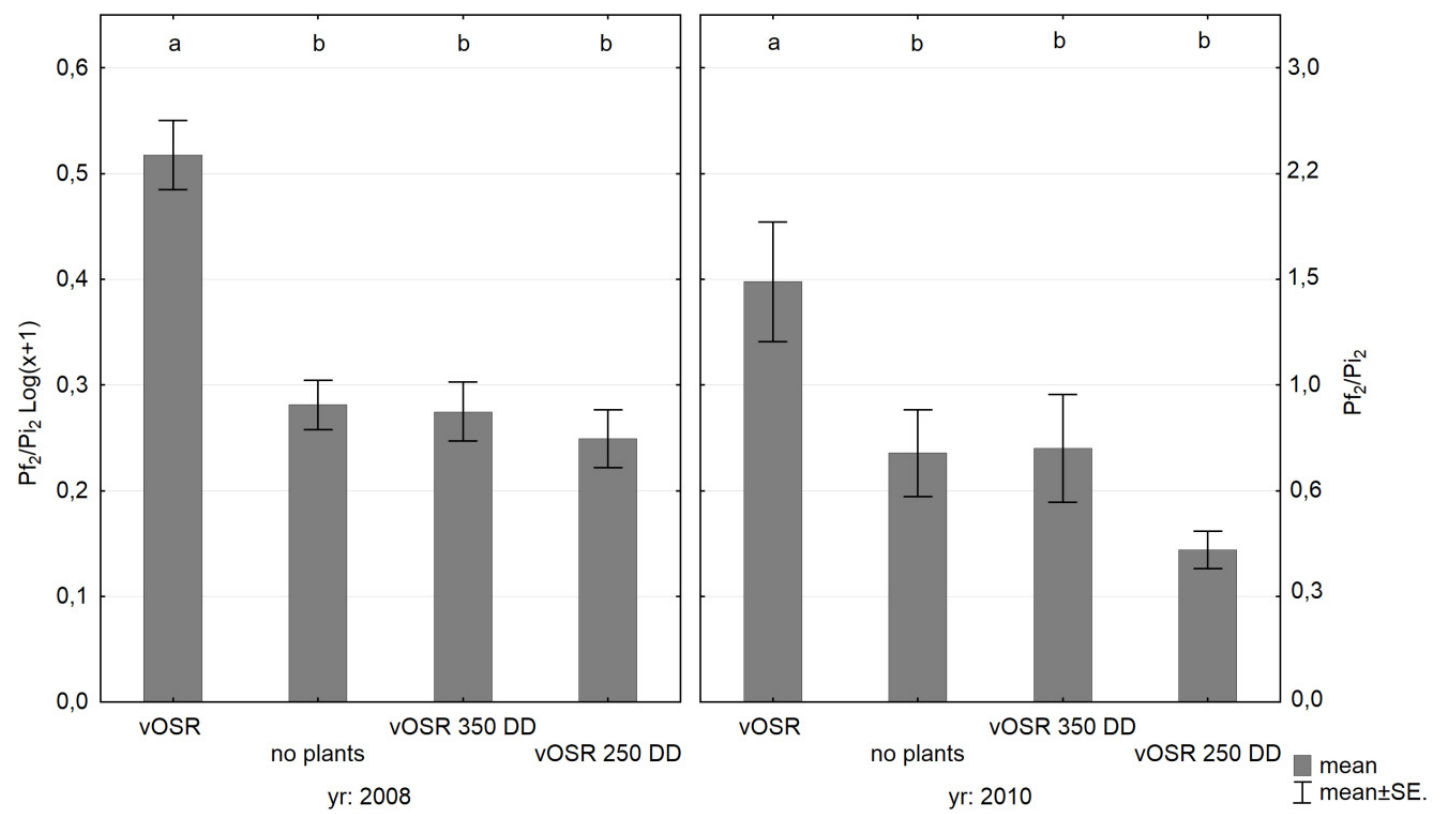

Figure 4. Multiplication rates Pf2/Pi2 ( $\log (x+1)$ transformed left axis; untransformed right axis) of beet cyst nematode $(\mathrm{BCN})$ under volunteer oilseed rape without control (vOSR) and after glyphosate treatment at 250 (vOSR $250 \mathrm{DD})$ or 350 (vOSR $350 \mathrm{DD})$ degree days $\left(>8{ }^{\circ} \mathrm{C}\right.$ ) or permanent control (no plants); means only within years were tested by Fischer LSD Test $(p<0.05)$, different letters indicate significant differences.

Table 4. Differences in multiplication rates $\mathrm{Pf} / \mathrm{Pi}$ and initial population densities (Pi) of beet cyst nematode $(\mathrm{BCN})$ as affected by treatments $(\mathrm{B})$ or year $(\mathrm{A})$ and cross- effects $\left(\mathrm{A}^{*} \mathrm{~B}\right)$ in a field trial with natural growth of volunteer oilseed rape (vOSR) and a micro-plot-trial with simulated volunteer oilseed rape (svOSR); ANOVA $(p<0.05)$ using $\log (x+1)$ transformed data for each trial separately.

\begin{tabular}{lcccc}
\hline & \multicolumn{2}{c}{ vOSR Field Trial } & \multicolumn{2}{c}{ svOSR Micro-Plot Trial } \\
\cline { 2 - 5 } & $\mathbf{P f}_{\mathbf{2}} / \mathbf{P i}_{\mathbf{2}}$ & $\mathbf{P i}_{\mathbf{2}}$ & $\mathbf{P f} / \mathbf{P i}$ & $\mathbf{P i}$ \\
\hline$P_{\text {treatment } A}$ & $<0.01$ & 0.08 & $<0.01$ & 0.49 \\
$P_{\text {year } B}$ & $<0.01$ & $<0.01$ & 0.59 & 0.71 \\
$P_{A^{*} B}$ & 0.62 & 0.11 & 0.12 & 0.07 \\
\hline
\end{tabular}

The population dynamics of BCN in plots with uncontrolled growth of vOSR showed distinctive differences from plots with a permanent growth suppression of plants (Figure 5). From 200 DD (23 days after emergence of vOSR in 2017) and 280 DD (26 days after emergence of vOSR in 2011) onwards, population density increased significantly in plots with vOSR $(p<0.036$, ANOVA), whereas population density in plots without plants did not change distinctively. Consequently, from 200 and 280 DD onwards, population densities in untreated plots showed significantly higher population densities then plots with complete growth suppression. 

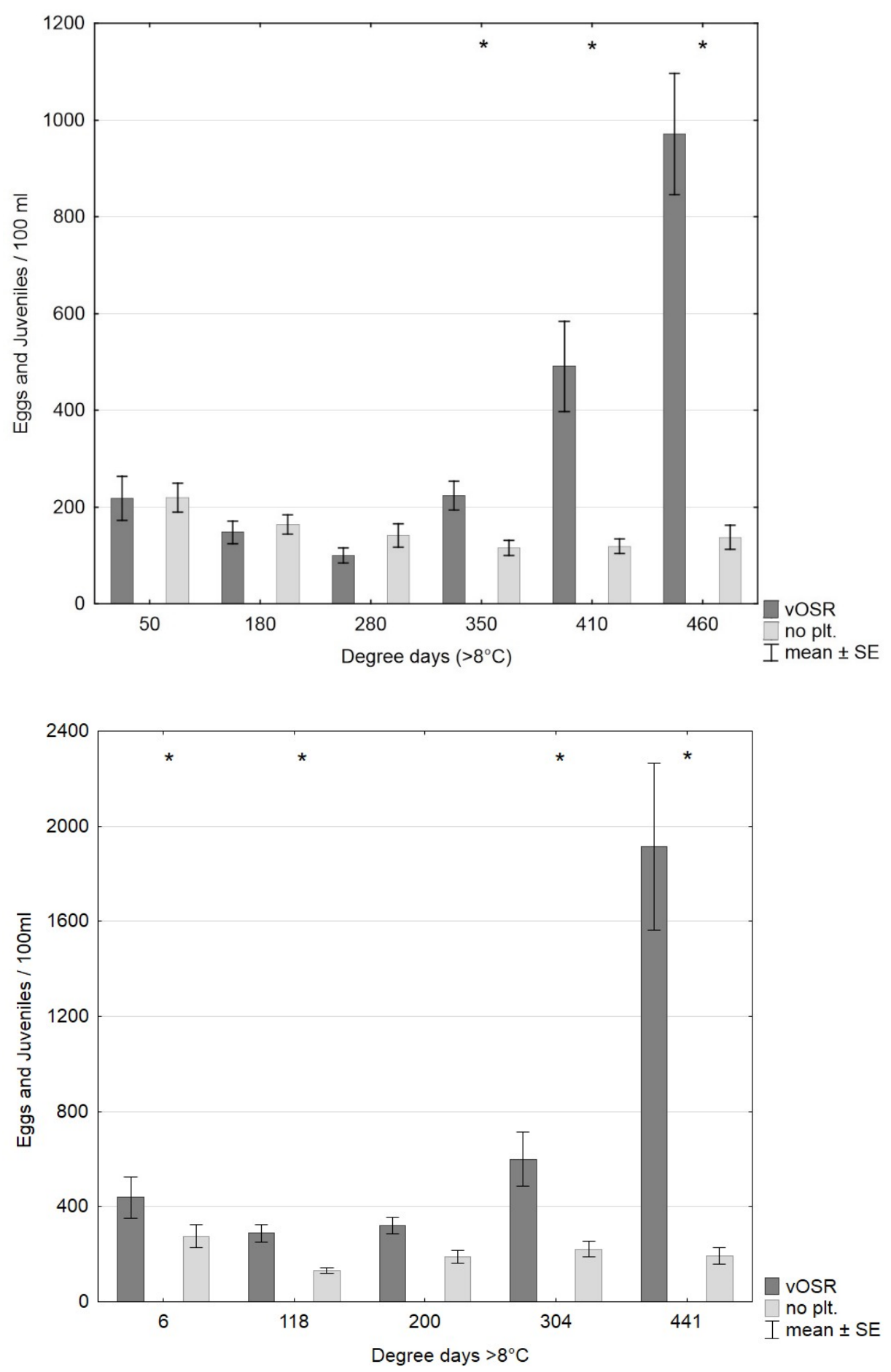

Figure 5. Population dynamics of beet cyst nematodes (BCN) during 460 (in 2016, below) and 441 (in 2011, above) degree days $\left(>8{ }^{\circ} \mathrm{C}\right.$ ) post winter oilseed rape cultivation under uncontrolled growth of volunteer oilseed rape (vOSR) and without plant coverage; ${ }^{*}$ Differences between treatments within degree days are significant if indicated using $t$-Test $(p<0.05)$.

\subsection{Micro-Plot Experiments on Effects of svOSR Treatments}

Sowing at high density to simulate volunteer oilseed rape (svOSR) resulted in a homogeneously distributed plant coverage in all micro-plots and in both years. The lowest multiplication rates of BCN were detected in plots where svOSR was controlled with glyphosate at 250 DD (Figure 6), whereas, in 2009, glyphosate treatments at later stages up to 350 DD showed significantly lower nematode 
reproduction than in the non-treated control plots. This effect could not be achieved in 2008. There was no effect on nematode reproduction between treatments at different degree days in both years. Combining all data from both years only the treatment effects on multiplication rates were found, but no effects by year. Initial population density remained independent between treatments and years (Table 4). A tendency for a higher multiplication rate of BCN in the non-treated control plots in 2009 in comparison to 2008 is associated with a similar higher temperature sum in 2009. At the time of Pf sampling, the temperature sum reached at $784 \mathrm{DD}$ on the 26th of October 2009 and achieved only $577 \mathrm{DD}$ at the 15th of October 2008.
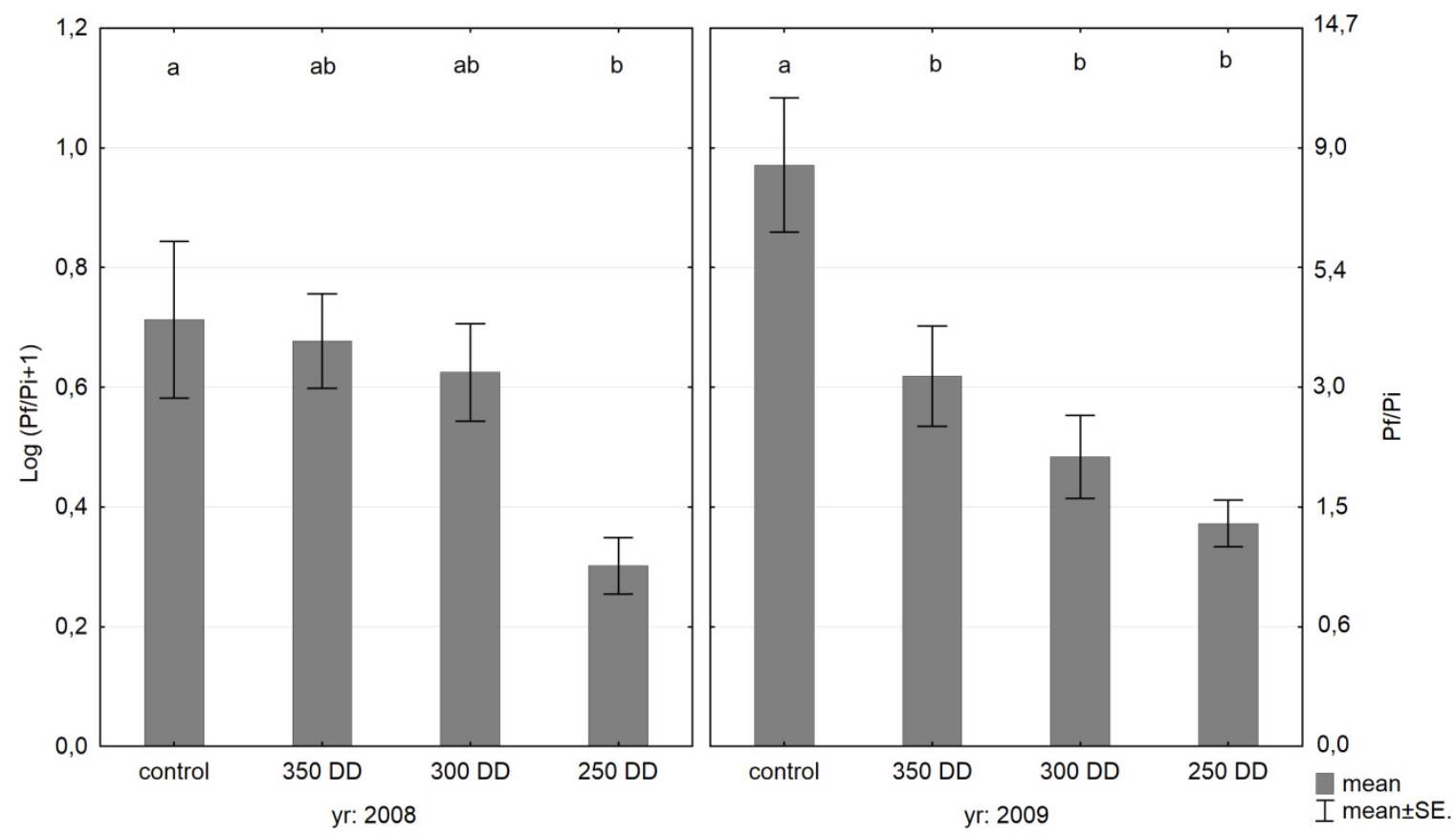

Figure 6. Multiplication rates $\mathrm{Pf} / \mathrm{Pi}(\log (x+1)$ transformed left axis; untransformed right axis) of beet cyst nematodes $(\mathrm{BCN})$ under simulated volunteer oilseed rape without control (svOSR) and after glyphosate treatment at 250 DD (svOSR 250 DD), at 300 DD (svOSR 300 DD) and 350 DD (svOSR 350 DD) in micro-plots; means only within years were tested by Fischer LSD Test $(p<0.05)$, different letters indicate significant differences.

\section{Discussion}

Results from pot experiments confirmed that oilseed rape (OSR) is a very good host of the BCN population used in this study. Accordingly, this has already been shown for other $\mathrm{BCN}$ populations for winter and spring OSR [3]. The development of the first successive BCN generation in OSR was shown 58 days after inoculation at $20^{\circ} \mathrm{C}$. In accordance with [12], the second invasion of $\mathrm{J} 2$ into roots at the end of the pot experiment can be interpreted as the end of the first generation. The relatively high population density of $\mathrm{J} 2$ in roots at the first sampling date does not conform to those reported by [12], which possibly might be explained by overestimation due to very low root weights at this time. High initial root penetration rates after exposition of $\mathrm{BCN}$ to OSR roots or its root exudates for one week were also observed by other researchers [6,22]. Due to the fact that cysts were used as inoculum in the present study, old cysts, in principal, also could have been a source for J2 at the second peek. This situation most likely also occurs under field conditions. The first emergence of females in both years was detected between 199 and $225 \mathrm{DD}\left(>8^{\circ} \mathrm{C}\right)$. The population density which originated from these females started to increase significantly in the period 200 to $350 \mathrm{DD}$. The eggs which develop inside these females are most likely virulent, taking into consideration that fertilization by males already starts before the onset of egg production [23]. Only 16 days, or approximately 200 DD later, population density of eggs and juveniles from the cyst fraction increased significantly, thus this period corresponds 
to the maturation period within which a majority of first-stage juveniles develop inside cysts [24,25]. However, reproduction already started at 200 DD and reached very high rates towards the end of the experiment, corresponding with the multiplication rates reported in [26].

Despite the very good host suitability of winter OSR, the multiplication rates of BCN under field conditions remained below those which are known for other host crops, like sugar beet [27], even though OSR shows higher susceptibility for BCN than sugar beet, due to a higher root surface which provides more sites for penetration [3]. A possible explanation for this could be lower maximum degree days over the vegetation period in comparison to sugar beet crop. In Germany, two to three generations could be verified in an outdoor experiment with a sugar beet crop [28]. Information on the essential degree days for the development of one $\mathrm{BCN}$ generation given in the literature and standardized to a basis of $8{ }^{\circ} \mathrm{C}$ varies between 425 and $550 \mathrm{DD}$ depending on the biological or physical reference parameters used $[25,29,30]$. The average maximum degree day achieved in the period 2000-2016, taking reference data (temperature in $10 \mathrm{~cm}$ soil depth) from the weather station Elsdorf in the reference vegetation time between 25th April and 8th October for sugar beet in Germany [31], was 1690 DD. The maximum degree days achieved during winter OSR cultivation until harvest remained below 1300 DD. This most likely explains the comparably low multiplication rate of 0.8 to 2.3 detected in winter OSR over the vegetation period, which is in accordance with other results [12,32]. Due to the relatively low distance of degree days of 120 to 140 DD between early and late sowing times, only non-significant tendencies in multiplication rates were observed, which can be explained by the Pi dependence of multiplication in nematodes [33]. Independent of drilling times, differences in multiplication rates between years were related to respective maximum degree days. In this respect, higher degree days in 2008 mainly resulted from increased temperatures in January and April to May. Specifically, the temperature regime in between January to May might play a key role in the second penetration of $\mathrm{J} 2$ into the roots of winter OSR and the formation of a second generation [12]. In this context, it is yet not clear if $\mathrm{BCN}$ can complete its life cycle in winter OSR until the temperature restricts further development and if non-completed stages continue development in the successive spring.

Results from field and micro-plot experiments showed that naturally germinated and svOSR produced distinctively higher multiplication rates post-harvest than the cultivation of OSR as a crop. A higher reproduction of $\mathrm{BCN}$ under volunteer oilseed rape (vOSR) can be explained by two major factors, which are the emergence of volunteer oilseed rape at periods of high soil temperatures and the very high plant densities of volunteers [15]. In accordance with results from the pot experiment, BCN population density significantly increased after $350 \mathrm{DD}$ in untreated plots, with gunimpeded growth of vOSR post-harvest. Consequently, control of vOSR before 350 DD in micro-plots, and likewise in field plots, prevented a multiplication of BCN. This effect was even greater when vOSR already was controlled at $250 \mathrm{DD}$, which was confirmed to be the period, where the first females start to occur. During the summer season, a daily increase in degree days might reach $12 \mathrm{DD}\left(>8^{\circ} \mathrm{C}\right)$, and thus the period within which 100 DD elapses could be as short as one week. As a result, there is only a very small time-window at which $\mathrm{BCN}$ reproduction under volunteer oilseed rape can be avoided. As the accumulation of degree days starts at the onset of emerging volunteers, the correct timing of this starting point is crucial for an effective control, especially when vOSR already starts to develop before harvest.

In the present study, vOSR was controlled chemically by the application of glyphosate. Mechanical control is an environmentally sound alternative to chemical controls. Though this method was not studied here, it is common practice in German agriculture. Mechanical control is often repeated post-harvest to achieve a maximum germination rate, and thus to reduce seed potential in the soil [34]. It is not clear if mechanical control is a convenient method to control BCN effectively, as plants might not die instantly and sometimes regain vitality depending on weather conditions. A combination of flat tillage (e.g., disc harrow) soon after harvest to increase germination of vOSR and a chemical control before $250 \mathrm{DD}\left(>8^{\circ} \mathrm{C}\right)$ could probably deliver a solution to effectively control both vOSR growth and $\mathrm{BCN}$ reproduction. 
Following a combination of greenhouse trials, micro-plot-experiments and field trials to investigate the importance of winter oilseed rape as a host crop for beet cyst nematode, volunteer oilseed rape could be identified as the major problem for integration in sugar beet rotation systems. Solutions were given to prevent the population increase of nematodes by controlling the unimpeded growth of volunteers. The results of this study were incorporated into the development of a simple degree day model to determine the effective time-window for the control of vOSR on the basis of data from local weather stations. This management tool [35] is available free of charge and is frequently used by growers and consultants.

Funding: This research received no external funding.

Acknowledgments: The present study was supported by public budget via internal funding of the Julius Kühn-Institute. The author greatly acknowledges the technical support by Hénocque-Piel, Schmitz, Hendelkes, Dinslaken, Kremer and Landwirtschaftlicher Informationsdienst Zuckerrübe (LIZ).

Conflicts of Interest: The author declare that he has no conflict of interest.

\section{References}

1. Müller, J. The economic importance of Heterodera schachtii in Europe. Helminthologia 1999, 36, 205-213.

2. Subbotin, S.A.; Mundo-Ocampo, M.; Baldwin, J.B. Systematics of Cyst Nematodes (Nematoda: Heteroderinae); Koninklijke Brill NV: Leiden, The Netherlands, 2010; Volume 8B, p. 512.

3. Nielsen, E.L.; Baltensperger, D.D.; Kerr, E.D.; Rife, C.L. Host suitability of rapeseed for Heterodera schachtii. J. Nematol. 2003, 35, 35-38. [PubMed]

4. Kühn, J. Die Ergebnisse der Versuch zur Ermittlung der Ursache der Rübenmüdigkeit und zur Erforschung der Natur der Nematoden; The Library of the University of California: Oakland, CA, USA, 1881; Volume 3, p. 153.

5. Rademacher, B.; Schmidt, O. Die bisherigen Erfahrungen in der Bekämpfung des Rübennematoden Heterodera schachtii Schm. auf dem Wege der Reizbeeinflussung. Arch. PflBau 1933, 10, $237-296$.

6. Lelivelt, C.L.C.; Hoogendoorn, J. The development of juveniles of Heterodera schachtii in roots of resistant and susceptible genotypes of Sinapis alba, Brassica napus, Raphanus sativus and hybrids. Neth. J. Plant Pathol. 1993, 99, 13-22. [CrossRef]

7. Evans, K.; Russell, M.D. The population-dynamics in microplots of brassica and beet cyst nematodes in rotations which include oilseed rape. Nematologica 1993, 39, 411-414.

8. Lelivelt, C.L.C.; Lange, W.; Dolstra, O. Intergeneric crosses for the transfer of resistance to the beet cyst-nematode from Raphanus sativus to Brassica napus. Euphytica 1993, 68, 111-120. [CrossRef]

9. Zhong, X.B.; Zhou, Q.Z.; Cui, N.; Cai, D.G.; Tang, G.X. BvcZR3 and BvHs1pro-1 Genes Pyramiding Enhanced Beet Cyst Nematode (Heterodera schachtii Schm.) Resistance in Oilseed Rape (Brassica napus L.). Int. J. Mol. Sci. 2019, 20, 1740. [CrossRef]

10. Goffart, H. Das Auftreten von Heterodera schachtii an Kreuzblütlern, namentlich an Raps und Rübsen. In Landwirtschaftliche Jahrbücher; Wiegandt \& Hempel: Berlin, Germany, 1947; Volume 93, p. 17.

11. Evans, K. Cyst nematode problems on oilseed rape. Asp. Appl. Biol. 1984, 6, 4.

12. Kakaire, S.; Grove, I.G.; Haydock, P.P.J. The number of generations of Heterodera schachtii completed on oilseed rape (Brassica napus L.) during the UK growing season. Nematology 2015, 17, 557-565. [CrossRef]

13. Ruosteenoja, K.; Markkanen, T.; Venalainen, A.; Raisanen, P.; Peltola, H. Seasonal soil moisture and drought occurrence in Europe in CMIP5 projections for the 21st century. Clim. Dynam. 2018, 50, 1177-1192. [CrossRef]

14. Wang, C.H.; Chen, Z.; Unteregelsbacher, S.; Lu, H.Y.; Gschwendtner, S.; Gasche, R.; Kolar, A.; Schloter, M.; Kiese, R.; Butterbach-Bahl, K.; et al. Climate change amplifies gross nitrogen turnover in montane grasslands of Central Europe in both summer and winter seasons. Glob. Chang. Biol. 2016, 22, 2963-2978. [CrossRef] [PubMed]

15. Weber, E.A.; Gruber, S.; Claupein, W. Emergence and performance of volunteer oilseed rape (Brassica napus) in different crops. Eur. J. Agron. 2014, 60, 33-40. [CrossRef]

16. Krato, C.; Petersen, J. Competitiveness and yield impact of volunteer oilseed rape (Brassica napus) in winter and spring wheat (Triticum aestivum). J. Plant Dis. Prot. 2012, 119, 74-82. [CrossRef]

17. Johnson, R.N.; Viglierchio, D.R. Sugar beet cyst nematode (Heterodera schachtii) reared on axenic Beta vulgaris. I. Selected environmental factors affecting penetration. Nematologica 1969, 15, 129-143. [CrossRef] 
18. Gruber, S.; Buhler, A.; Mohring, J.; Claupein, W. Sleepers in the soil-Vertical distribution by tillage and long-term survival of oilseed rape seeds compared with plastic pellets. Eur. J. Agron. 2010, 33, 81-88. [CrossRef]

19. Kühn, J. Neuere Versuche zur Bekämpfung der Rübennematoden. In Centralblatt für Bakteriologie und Parasitenkunde; Verlag v. Gustav Fischer: Jena, Germany, 1891; Volume 9, pp. 563-566, 593-597.

20. Müller, J.; Rumpenhorst, H.J. Die Prüfung von Pflanzen auf Ihre Widerstandsfähigkeit gegen Schadorgansimen in der Biologischen Bundesanstalt. In Testing of Crop Cultivars for Resistance to Noxious Organisms at the Federal Biological Research Centre; Müller, J., Rumpenhorst, H.J., Eds.; Wiegandt, Hempel \& Parey: Berlin, Germany, 2000; Volume 372, p. 38.

21. Müller, J. Ein verbessertes Extraktionsverfahren für Heterodera schachtii. Nachrichtenbl. Deut. Pflanzenschutzd. 1980, 32, 21-24.

22. Fatemy, S.; Abootorabi, E. Hatching activity, invasion rate and reproduction of Heterodera schachtii on oilseed rape cultivars. Nematol. Mediterr. 2002, 30, 163-166.

23. Koenning, S.R.; Sipes, B.S. Biology. In The Cyts Nematodes; Sharma, S.B., Ed.; Chapmann and Hall: London, UK, 1998.

24. Gardner, J.; CaswellChen, E.P. Influence of cyst maturation on apparent population increases of Heterodera schachtii on root remnants. Fundam. Appl. Nematol. 1997, 20, 269-276.

25. Caswell, E.P.; Thomason, I.J. A model of egg-production by Heterodera-schachtii (Nematoda, Heteroderidae). Can. J. Zool. 1991, 69, 2085-2088. [CrossRef]

26. Kazlauskaite, S.; Coosemans, J. Reproductive rate of the Heterodera schachtii on different winter rapeseed cultivars. Lž̄u Moksl. Darb. 2009, 83, 38-42.

27. Kenter, C.; Lukashyk, P.; Daub, M.; Ladewig, E. Population dynamics of Heterodera schachtii Schm. and yield response of susceptible and resistant sugar beet (Beta vulgaris L.) after cultivation of susceptible and resistant oilseed radish (Raphanus sativus L.). J. Kult. 2014, 66, 289-299.

28. Müller, J. Über die Generationenzahl von Heterodera schachtii unter Feldbedingungen an Zuckerrüben. Nach. Dtsch. Pflanzenschutzd. 1979, 31, 92-95.

29. Čuri, J.; Zmoray, I. Beziehung klimatischer Faktoren zur Entwicklungsdauer von Heterodera schachtii in der Slowakei (CSSR). Helminthologia 1966, 7, 49-63.

30. Griffin, G.D. Factors affecting the biology and pathogenicity of Heterodera-schachtii on sugar beets. J. Nematol. 1988, 20, 396-404. [PubMed]

31. DWD. Available online: https:/opendata.dwd.de/climate_environment/CDC/observations_germany/ phenology/annual_reporters/crops/historical/) (accessed on 5 May 2019).

32. Dobosz, R.; Kornobis, S. Population Dynamics of Sugar-Beet Cyst Nematode (Heterodera schachtii) On Spring and Winter Oilseed Rape Crops. J. Plant Prot. Res. 2008, 48, 237-245. [CrossRef]

33. Seinhorst, J.W. Dynamics of Populations of Plant Parasitic Nematodes. Ann. Rev. Phytopathol. 1970, 8 , 131-156. [CrossRef]

34. Pekrun, C.; Lutman, P.J.W.; Buchse, A.; Albertini, A.; Claupein, W. Reducing potential gene escape in time by appropriate post-harvest tillage-Evidence from field experiments with oilseed rape at 10 sites in Europe. Eur. J. Agron. 2006, 25, 289-298. [CrossRef]

35. LIZ. Ausfallrapsmanager. Available online: http://raps.rheinmedia.de/raps/index.php (accessed on 15 May 2019).

(C) 2020 by the author. Licensee MDPI, Basel, Switzerland. This article is an open access article distributed under the terms and conditions of the Creative Commons Attribution (CC BY) license (http://creativecommons.org/licenses/by/4.0/). 